\title{
Age-dependent increase of treatment-related mortality in older patients with aggressive B cell lymphoma: analysis of outcome, treatment feasibility, and toxicity in 1171 elderly patients with aggressive B cell lymphoma-data from phase II and III trials of the DSHNHL (German High-Grade Non-Hodgkin's Lymphoma Study Group)
}

\author{
Florian Zettl ${ }^{1}$ • Marita Ziepert ${ }^{2}$ - Bettina Altmann ${ }^{2}$. Samira Zeynalova ${ }^{2} \cdot$ Gerhard Held $^{3} \cdot$ Viola Pöschel $^{3}$. \\ Karin Hohloch ${ }^{4,5} \cdot$ Gerald G. Wulf $^{4} \cdot$ Bertram Glass $^{6} \cdot$ Norbert Schmitz $^{7}$ • Markus Loeffler ${ }^{2}$ - Lorenz Trümper ${ }^{4}$
}

Received: 14 July 2020 / Accepted: 11 November 2020 / Published online: 26 November 2020

(C) The Author(s) 2020

\begin{abstract}
In elderly patients (pts) with aggressive B cell lymphoma (aNHL), curative treatment often cannot be administered because of comorbidities and tolerability. We analyzed the influence of age in pts $>60$ years receiving the R-CHOP-14 regimen within different prospective DSHNHL trials. Of the RICOVER-60 trial and CHOP-R-ESC trials, $1171 \mathrm{aNHL}$ pts were included in this retrospective analysis of age-dependent event-free survival (EFS), progression-free survival (PFS), and overall survival (OS). All patients received prophylactic G-CSF, and anti-infective prophylaxis with amphotericin B mouth wash and oral fluorchinolone was optional. In the CHOP-R-ESC trials, prophylaxis was augmented to include mandatory continuous orally administered aciclovir and a pneumocystis prophylaxis with cotrimoxazole as well as oral fluorchinolones during neutropenia. The patient population was separated into 4 age groups (61-65 years, 66-70 years, 71-75 years, and 76-80 years). The results from the RICOVER-60 trial were subsequently confirmed in the following CHOP-R-ESC trials by a multivariate analysis adjusted for IPI factors and gender. Significant differences $(p<0.001)$ in EFS, PFS, and OS were seen between age groups (RICOVER-60).
\end{abstract}

Florian Zettl and Marita Ziepert contributed equally to this work.

Supported by Deutsche Krebshilfe, dedicated to Michael Pfreundschuh (deceased) former chairman and founder of the German High-Grade NonHodgkin's Lymphoma Study Group, outstanding scientist, and clinician

Presented at the Annual Meeting of the American Society of Clinical Oncology, 2016 (Reference: Age-dependent analysis of toxicity, mortality, and implementation of an anti-infective prophylaxis in 1171 elderly patients (pts) with aggressive B-cell lymphoma (aNHL): Data from consecutive phase II and III trials of the DSHNHL. Florian Zettl, Marita Ziepert, Bettina Altmann, Samira Zeynalova, Markus Loeffler, Norbert Schmitz, Michael Pfreundschuh, Karin Hohloch, and Lorenz Trümper; Journal of Clinical Oncology 2016 34:15_suppl, 7539-7539)

Florian Zettl

florian.zettl@kliniken-sob.de

1 Department of Hematology, Oncology and Palliative Care, Klinikum Traunstein, Traunstein, Germany

2 Institute for Medical Informatics, Statistics and Epidemiology, University of Leipzig, Leipzig, Germany

3 Department of Internal Medicine, University Hospital Saarland, Homburg, Germany
4 Department of Hematology and Medical Oncology, Georg August University Göttingen, Göttingen, Germany

5 Hematology and Oncology, Kantonsspital Graubünden, Chur, Switzerland

6 Department of Hematology, Oncology, and Tumor Immunology, Helios Klinikum Berlin-Buch, Berlin, Germany

7 Department of Internal Medicine A, University of Münster, Münster, Germany 
Hematotoxicity, infections, and TRM increased with age. TRM was significantly elevated in the age group 76-80 years. Therefore, this analysis shows that an age above 75 years defines an especially vulnerable patient population when being treated with chemoimmunotherapy for aNHL. Prophylactic anti-infective drugs are essential and clinically effective in reducing morbidity when treating elderly aNHL pts.

Keywords Aggressive lymphoma $\cdot$ Diffuse large cell lymphoma $\cdot$ Elderly patients $\cdot$ Treatment-related mortality $\cdot$ Infections

\section{Introduction}

Aggressive B cell lymphomas (aNHL) are a heterogeneous group of aggressive B cell neoplasms including diffuse large B cell lymphoma (DLBCL), the most frequent lymphoid neoplasia accounting for one-third of all malignant lymphomas. R-CHOP (rituximab, cyclophosphamide, doxorubicin, vincristine, and prednisolone) is the current treatment standard, leading to high cure rates especially in younger patients [1]. The incidence of aNHL, however, increases with age, and almost $50 \%$ of patients are older than 60 years [2]. In older patients, prognosis is almost identical to that of younger individuals if patients can be treated with full-dose immunochemotherapy, as demonstrated in several large phase III trials $[2,3]$. However, administration of fully dosed chemotherapy is limited by the age-dependent increase of comorbidities and higher treatment-related mortality (TRM) [4]. Dose reductions are frequent and correlate with an inferior prognosis [5]. Supportive measures such as growth factor support and anti-infective prophylaxis are recommended by the American Society of Clinical Oncology (ASCO) [6] in order to facilitate treatment at full dose and reduce toxicity. Here we analyzed the feasibility and toxicity of the R-CHOP-14 regimen within consecutive prospective DSHNHL phase II and III trials (RICOVER-60, DENSE-R-, SMARTE-R-, and SEXIER-CHOP-14) for patients between 60 and 80 years of age. We investigated the impact of age on the outcome, feasibility, and toxicity of lymphoma therapy by dividing the patient population into four age groups (61-65 years, 66-70 years, 71-75 years, and 76-80 years). Furthermore, we analyzed whether the implementation of a stringent anti-infective prophylaxis as implemented in the most recent trial populations is able to reduce the treatment-related mortality (TRM).

\section{Material and methods}

\section{Patients and treatment}

Since 2000, 1823 patients (pts) with aggressive B cell lymphoma between the age of 61 and 80 years were treated in DSHNHL (German High-Grade Non-Hodgkin's Lymphoma Study Group) phase III trials RICOVER-60 and consecutive phase-II CHOP-R-ESC trials: DENSE-R-, SMARTE-R-, and SEXIE-R-CHOP-14. The RICOVER-60 trial was a four- armed randomized phase III trial analyzing the impact of 8 applications rituximab (R-CHOP-14 versus CHOP-14) as well as the impact of two additional cycles of CHOP-14 (6 versus 8 cycles) on the outcome of elderly patients with aggressive lymphoma [3]. A total of 1242 patients have been recruited into the RICOVER- 60 trial of whom 620 patients were randomized to R-CHOP-14; 610 patients with not withdrawn informed consent were included in this analysis. The aim of the subsequent CHOP-R-ESC phase II trials was to optimize the rituximab application in combination with $6 \mathrm{cy}$ cles CHOP-14 chemotherapy in patients between the age of 61 and 80 years with newly diagnosed aggressive B-NHL. The results of these trials were compared with the data of the RICOVER-60 trial. In the first, the DENSE-R-CHOP-14 trial, patients received in total 12 applications of rituximab (days $0,1,4,8,15,22,29,43,57,71,85$, and 99) with 4 additional infusions of rituximab within the first 3 weeks of 6 cycles of CHOP-14. The primary end point was the assessment of pharmacokinetics (in the first 20 patients) and the safety of this rituximab application scheme [7]. In the second, the SMARTE-R-trial, patients received 8 cycles of rituximab; however, patients received a loading dose of $\mathrm{R}$ and were exposed to rituximab for a longer period of time (on days 4,0 , $10,29,57,99,155$, and 239). The primary endpoint was the evaluation of the pharmacokinetics, safety, and toxicity of this extended rituximab therapy [8]. The third, the SEXIE-RCHOP-14 trial, evaluated the role of 8 applications of rituximab with dose escalation in male patients $\left(500 \mathrm{mg} / \mathrm{m}^{2}\right.$ rituximab) to overcome the poorer prognosis of elderly male patients compared to their female counterparts. The primary objective of the SEXIE-R trial was the evaluation of the pharmacokinetics, safety, and toxicity of the upfront dose-dense rituximab schedule and the increased dose of $500 \mathrm{mg} / \mathrm{m} 2$ for elderly males [9]. All patients were to receive G-CSF from days 4 to 13 and an anti-infective prophylaxis with amphotericin B mouth wash starting at day 7 of each cycle until recovery of leukocytes $>1000 / \mu$ l; oral fluorchinolone prophylaxis was optional. After a safety analysis at the time when 20 patients had been included into the DENSE-R-study had shown increased toxicity, prophylaxis in the CHOP-RESC trials was augmented to include mandatory oral fluorchinolones (starting day 6 of each cycle until recovery of leukocytes $>1000 / \mu \mathrm{l})$, oral aciclovir $(4 \times 400 \mathrm{mg} /$ day $)$, and pneumocystis prophylaxis with cotrimoxazole $(960 \mathrm{mg}, 2 \mathrm{tab}-$ lets on 2 consecutive days per week). We finally included 
1171 pts with aggressive NHL receiving rituximab-based chemoimmunotherapy in the RICOVER-60 $(n=610)$, the DENSE-R- ( $n=104 / 124$ the first 20 patients without mandatory anti-infective prophylaxis were excluded), SMARTE-R( $n=189)$, and the SEXIE-R-CHOP-14 trial $(n=268)$ into an analysis of event-free survival (EFS), progression-free survival (PFS), and overall survival (OS). TRM and the impact of augmented anti-infective prophylaxis, established within the CHOP-R-ESC trials, were investigated in comparison to the RICOVER-60 trial. We subdivided the population into 4 age groups (61-65 years, 66-70 years, 71-75 years, and 76-80 years) to analyze the outcome, feasibility, toxicity, and the effects of prophylaxis in an age-dependent manner.

\section{Statistical analysis}

Event-free survival (EFS) as the primary endpoint of the RICOVER-60/CHOP-R-ESC trials was defined as the time from randomization/registration to disease progression, start of salvage treatment, additional (unplanned) treatments, relapse, or death from any cause. Progression-free survival (PFS) was defined as time from randomization/registration to disease progression, relapse, or death from any cause. Overall survival (OS) was defined as the time from randomization/ registration to death from any cause. EFS, PFS, and OS were estimated according to Kaplan and Meier [10].

The separation of patients into the 4 age groups (61-65 years, 66-70 years, 71-75 years, and 76-80 years) resulted from a martingale residual analyses. Within the four age groups, univariable outcome analyses were performed, and log-rank tests are presented. Proportional hazard models for the four age groups were adjusted for the factors of the International Prognostic Index (IPI, i.e., lactate dehydrogenase $(\mathrm{LDH})>$ normal, ECOG $>1$, stages III/IV, and extranodal involvement $>1$ ) and gender. Hazard ratios $(\mathrm{HR})$ with 95\% confidence intervals $(\mathrm{CI})$ and $p$ values are presented. For comparison of age groups regarding patient characteristics, infections CTC grades $3 / 4$ and treatment-related mortality (TRM) chi-square and, if necessary, Fisher's exact tests were used. For the estimation of the relative dose of doxorubicin (representing the protocol adherence of CHOP therapy), the body surface area (BSA) was assessed according to DuBois et al. [11] for each of the cycles. With these values, we assessed for all patients the absolute dose of doxorubicin (mg) given per BSA $\left(\mathrm{m}^{2}\right)$ for each cycle. The relative dose of doxorubicin was then calculated as the sum of given doses $\left(\mathrm{mg} / \mathrm{m}^{2}\right)$ over the cycles divided by the planned dose for $6\left(6 \times 50 \mathrm{mg} / \mathrm{m}^{2}\right)$ cycles according to RICOVER-60/CHOP-R-ESC protocol. Curves of relative dose were estimated according to Kaplan and Meier technique [12].

The significance level was set at $p=0.05$ (two-sided). Statistical analyses were done with IBM SPSS Statistics 22 software (SPSS, Chicago, IL).

\section{Results}

In 1144 of 1171 patients (98\%), a reference pathological diagnosis was available, and 946 of 1144 patients were diagnosed with DLBCL (83\%). The clinical characteristics and IPI risk factors of the four age groups are shown in Tables 1 and 2
Table 1 RICOVER-60 studyage groups patients $61-80$ years, 6 -CHOP-14 + 8xR $(n=306)$ demographics

\begin{tabular}{lllll}
\hline & $\begin{array}{l}61-65 \text { years } \\
n=90\end{array}$ & $\begin{array}{l}66-70 \text { years } \\
n=103\end{array}$ & $\begin{array}{l}71-75 \text { years } \\
n=73\end{array}$ & $\begin{array}{l}76-80 \text { years } \\
n=40\end{array}$ \\
\hline Male & $54(60 \%)$ & $59(57 \%)$ & $34(47 \%)$ & $21(52 \%)$ \\
Female & $36(40 \%)$ & $44(43 \%)$ & $39(53 \%)$ & $19(48 \%)$ \\
Age, median (range) & $62(61,65)$ & $68(66,70)$ & $73(71,75)$ & $78(76,80)$ \\
LDH $>$ UNV & $39(43 \%)$ & $45(44 \%)$ & $37(51 \%)$ & $31(78 \%)$ \\
ECOG $>1$ & $13(14 \%)$ & $10(10 \%)$ & $9(12 \%)$ & $11(28 \%)$ \\
Stage III/IV & $52(58 \%)$ & $50(48 \%)$ & $26(36 \%)$ & $24(60 \%)$ \\
Extranod. involvement $>1$ & $17(19 \%)$ & $21(20 \%)$ & $6(8 \%)$ & $8(20 \%)$ \\
IPI 1 & $29(32 \%)$ & $34(33 \%)$ & $26(36 \%)$ & $5(12 \%)$ \\
2 & $24(27 \%)$ & $32(31 \%)$ & $23(32 \%)$ & $10(25 \%)$ \\
3 & $22(24 \%)$ & $24(23 \%)$ & $19(26 \%)$ & $13(32 \%)$ \\
4,5 & $15(17 \%)$ & $13(13 \%)$ & $5(7 \%)$ & $12(30 \%)$ \\
Extranod. involvem. & $40(44 \%)$ & $59(57 \%)$ & $43(59 \%)$ & $19(48 \%)$ \\
Bulky disease & $42(47 \%)$ & $36(35 \%)$ & $22(30 \%)$ & $17(42 \%)$ \\
B symptoms & $36(40 \%)$ & $26(25 \%)$ & $23(32 \%)$ & $13(32 \%)$ \\
BM involvement & $4(4 \%)$ & $5(5 \%)$ & $2(3 \%)$ & $3(8 \%)$ \\
\hline
\end{tabular}


Table 2 CHOP-R-ESC trialsage groups patients $61-80$ years $(n=561)$ demographics

\begin{tabular}{lrllr}
\hline & $\begin{array}{l}61-65 \text { years } \\
n=149\end{array}$ & $\begin{array}{l}66-70 \text { years } \\
n=188\end{array}$ & $\begin{array}{l}71-75 \text { years } \\
n=141\end{array}$ & $\begin{array}{l}\text { 76-80 years } \\
n=83\end{array}$ \\
\hline Male & $94(63 \%)$ & $103(55 \%)$ & $74(52 \%)$ & $32(39 \%)$ \\
Female & $55(37 \%)$ & $85(45 \%)$ & $67(48 \%)$ & $51(61 \%)$ \\
Age, median (range) & $63(61,65)$ & $68(66,70)$ & $73(71,75)$ & $77(76,80)$ \\
LDH > UNV & $78(52 \%)$ & $99(53 \%)$ & $73(52 \%)$ & $47(57 \%)$ \\
ECOG > 1 & $12(8 \%)$ & $25(13 \%)$ & $17(12 \%)$ & $16(19 \%)$ \\
Stage III/ IV & $95(64 \%)$ & $112(60 \%)$ & $84(60 \%)$ & $52(63 \%)$ \\
Extranod. involvement $>1$ & $48(32 \%)$ & $57(30 \%)$ & $42(30 \%)$ & $23(28 \%)$ \\
IPI 1 & $37(25 \%)$ & $47(25 \%)$ & $36(26 \%)$ & $16(19 \%)$ \\
2 & $32(22 \%)$ & $45(24 \%)$ & $34(24 \%)$ & $24(29 \%)$ \\
3 & $49(33 \%)$ & $51(27 \%)$ & $40(28 \%)$ & $20(24 \%)$ \\
4,5 & $31(21 \%)$ & $45(24 \%)$ & $31(22 \%)$ & $23(28 \%)$ \\
Extranod. involvem. & $99(66 \%)$ & $123(65 \%)$ & $99(70 \%)$ & $47(57 \%)$ \\
Bulky disease & $52(35 \%)$ & $67(36 \%)$ & $52(37 \%)$ & $31(37 \%)$ \\
B symptoms & $42(28 \%)$ & $63(34 \%)$ & $41(29 \%)$ & $21(25 \%)$ \\
BM involvement & $13(9 \%)$ & $17(9 \%)$ & $13(9 \%)$ & $3(4 \%)$ \\
\hline
\end{tabular}

and the supplement Table 1. Subdividing the two study cohorts RICOVER-60 and CHOP-R-ESC into the four age groups within RICOVER-60 trial (6/8-CHOP-14 + 8xR) revealed significantly increased numbers of female patients $(p<$ $0.001)$, more elevated LDH values $(p=0.003)$, and worse ECOG $>1$ performance scores $(p=0.001)$ in elderly age groups (supplement Table 1) and within CHOP-R-ESC trials significantly more female patients $(p=0.004)$ and a trend to worse ECOG $>1$ performance scores $(p=0.097)$ for the patients from elderly age groups (Table 2). Dose reductions were most frequent in the age group 76-80 years, however, to a smaller extent in the CHOP-R-ESC trial (Fig. 1 and Fig. 2); up to $70 \%$ of these pts from RICOVER-60 trial did not receive the complete chemotherapy as planned (Table 4). Hematotoxicity, infections, and TRM increased with age.

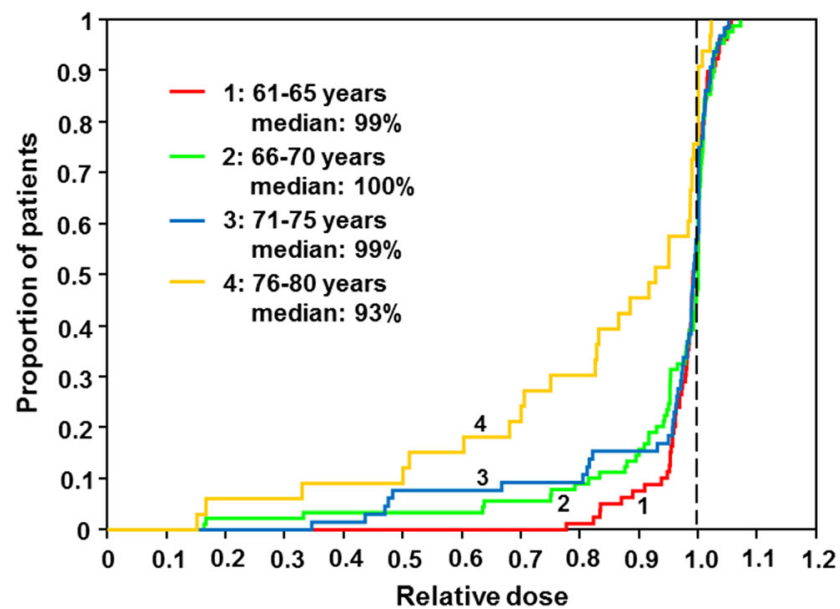

Fig. 1 Relative dose doxorubicin RICOVER-60 study-age groups patients 61-80 years, 6-CHOP- $14+8 \times R(n=306)$
TRM was significantly higher $(p=0.029)$ for the age group 76-80 years (amounting to $11 \%$ in the CHOP-R-ESC trials) as compared to $4 \%$ for the age group 71-75 years (Tables 3 and 4). In comparison, in the RICOVER-60 trial, TRM for 6CHOP-14 $+8 \times$ R was $20 \%$ and $8 \%$, respectively $(p=0.081)$. Higher TRM (but not higher mortality due to lymphoma) resulted in significant inferior EFS, PFS, and OS in the age group 76-80 years as compared to patients aged 71-75 years in both trials (RICOVER-60 3 years EFS, 44\% (95\% CI: 28 59) versus $68 \%$ (95\% CI: 56-78) $p<0.001$; PFS, $49 \%(95 \%$ CI: 33-64) versus $78 \%$ (95\% CI: 68-88) $p<0.001$; OS, $51 \%$ (95\% CI: 36-67) versus 80\% (95\% CI: 70-89) $p<0.001$ (Table 3, Fig. 3); R-CHOP-ESC 3-years EFS, 53\% (95\% CI: 42-64) versus $71 \%$ (95\% CI: 63-78) $p=0.011$; PFS, $57 \%$ (95\% CI: 46-68) versus 74\% (95\% CI: 67-81) $p=0.011$; OS,

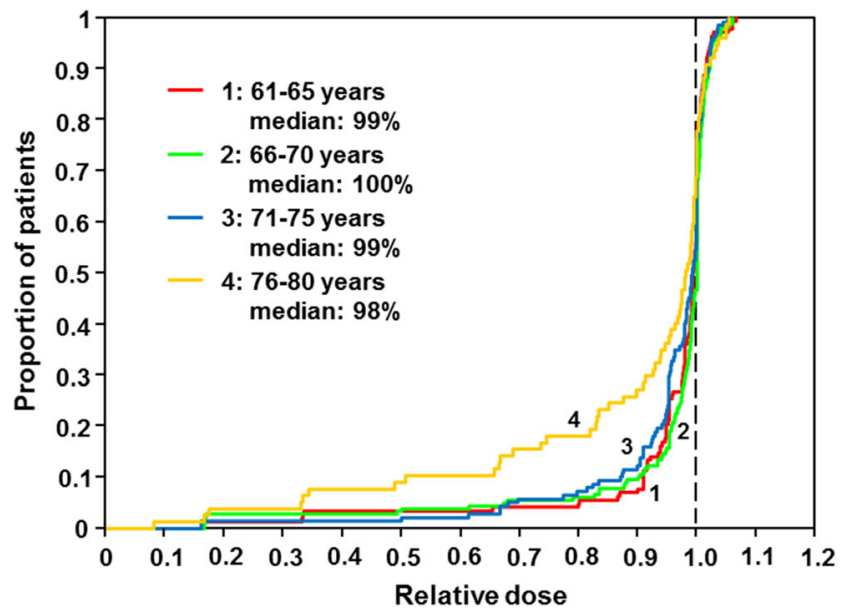

Fig. 2 Relative dose doxorubicin CHOP-R-ESC study - age groups patients $61-80$ years $(n=561)$ 
Table 3 Comparison of survival data, treatment-related mortality, and rate of infections between the age groups in the RICOVER-60 and CHOP-R-ESC trials

\begin{tabular}{|c|c|c|c|c|c|c|}
\hline & $\begin{array}{l}\text { Age } \\
\text { Years }\end{array}$ & $\begin{array}{l}\text { EFS } \\
\text { 3-year rate }\end{array}$ & PFS & OS & TRM & $\begin{array}{l}\text { Infections } \\
\text { CTC } \\
\text { grade } 3,4\end{array}$ \\
\hline \multicolumn{7}{|l|}{ RICOVER-60 trial } \\
\hline \multicolumn{7}{|l|}{$6 \mathrm{xCHOP}-14+8 \mathrm{R}(n=306)$} \\
\hline$n=90$ & $61-65$ & $72 \%$ & $78 \%$ & $85 \%$ & $0 \%$ & $24 \%$ \\
\hline$n=103$ & $66-70$ & $70 \%$ & $72 \%$ & $79 \%$ & $3 \%$ & $20 \%$ \\
\hline$n=73$ & $71-75$ & $68 \%$ & $78 \%$ & $80 \%$ & $8 \%$ & $33 \%$ \\
\hline$n=40$ & $76-80$ & $44 \%$ & $49 \%$ & $51 \%$ & $20 \%$ & $44 \%$ \\
\hline$p$ values (all age groups) & & $p<0.001$ & $p<0.001$ & $p<0.001$ & $p<0.001$ & $p=0.025$ \\
\hline$p$ values ( $76-80$ vs. $71-75$ years) & & $p<0.001$ & $p<0.001$ & $p<0.001$ & $p=0.081$ & $p=0.263$ \\
\hline \multicolumn{7}{|l|}{ CHOP-R-ESC trials $(n=561)$} \\
\hline$n=149$ & $61-65$ & $74 \%$ & $78 \%$ & $85 \%$ & $1 \%$ & $10 \%$ \\
\hline$n=188$ & $66-70$ & $68 \%$ & $75 \%$ & $80 \%$ & $4 \%$ & $18 \%$ \\
\hline$n=141$ & $71-75$ & $71 \%$ & $74 \%$ & $77 \%$ & $4 \%$ & $24 \%$ \\
\hline$n=83$ & $76-80$ & $55 \%$ & $57 \%$ & $61 \%$ & $11 \%$ & $28 \%$ \\
\hline$p$ values (all age groups) & & $p=0.025$ & $p=0.007$ & $p=0.001$ & $p=0.011$ & $p=0.001$ \\
\hline$p$ values (76-80 vs. $71-75$ years) & & $p=0.011$ & $p=0.011$ & $p=0.045$ & $p=0.029$ & $p=0.501$ \\
\hline
\end{tabular}

$61 \%$ (95\% CI: 50-72) versus $77 \%(95 \% \mathrm{CI}: 70-84) p=$ 0.045 ) (Table 3, Fig. 4). Multivariate analysis of the four age groups adjusted for IPI-factors and gender showed similar results with significant hazard ratios (HR) only between age groups 76-80 years and 71-75 years (RICOVER-60: EFS, $\mathrm{HR}=1.9$ (95\% CI: 1.1-3.1) $p=0.020 ; \mathrm{PFS}, \mathrm{HR}=2.3(95 \%$ CI: $1.3-4.1) p=0.004 ;$ OS, HR $=2.2(95 \%$ CI: $1.3-4.0) p=$ 0.006; CHOP-R-ESC: EFS, HR = 1.7 (95\% CI: 1.1-2.7) $p=$ 0.013; PFS, HR = $1.8(95 \% \mathrm{CI}: 1.1-2.8) p=0.011$; OS, $\mathrm{HR}=$ 1.6 (95\% CI: $1.0-2.5) p=0.051)$.

Because of increased infectious complications seen in the first 20 patients included in the DENSE-R-trial, the DSHNHL introduced a stringent anti-infective prophylaxis for all subsequent patients treated in all CHOP-R-ESC trials. Adherence to this schedule was almost complete (61-65 years, 93\%; 66-70 years, 92\%; 71-75 years. 89\%; and 7680 years, $91 \%$ ) compared to the much lower percentage of patients receiving prophylaxis in the preceding RICOVER60 trial (6xCHOP-14 + 8xR: 33\%, 36\%, 33\%, 41\%) resulting in higher numbers of patients being treated with interventional antibiotics $(49 \%, 52 \%, 59 \%, 53 \%)$ compared to a much lower number of patients in the R-CHOP-ESC trials $(26 \%, 31 \%$, $36 \%$, and $48 \%$ ). The rate of grades 3 and 4 infections per patient was also different in these two patient cohorts with significantly lower numbers in the R-CHOP-ESC trials (19\%) in comparison to the RICOVER-60 trial for

Table 4 Course of chemotherapy according to age groups for 6/8-CHOP-14 + 8xR (RICOVER-60 trial) and CHOP-R-ESC trials

\begin{tabular}{|c|c|c|c|c|c|c|}
\hline \multirow[t]{2}{*}{ Course of chemotherapy } & & \multicolumn{4}{|c|}{$\%$ of age group } & \multirow[t]{2}{*}{ Total } \\
\hline & & $61-65$ years & $66-70$ years & $71-75$ years & $76-80$ years & \\
\hline \multirow[t]{3}{*}{ RICOVER-60 trial 6-CHOP-14 + 8xR } & $n$ & 90 & 103 & 73 & 40 & 306 \\
\hline & Regular & $82(91 \%)$ & $92(89 \%)$ & $56(77 \%)$ & $26(65 \%)$ & $256(84 \%)$ \\
\hline & Non-regular because of toxicity & $2(2 \%)$ & $7(7 \%)$ & $10(14 \%)$ & $13(33 \%)$ & $32(11 \%)$ \\
\hline \multirow[t]{3}{*}{ RICOVER-60 trial 8-CHOP-14 + 8xR } & $n$ & 108 & 85 & 71 & 40 & 304 \\
\hline & Regular & $83(77 \%)$ & $54(64 \%)$ & $42(59 \%)$ & $12(30 \%)$ & $191(63 \%)$ \\
\hline & Non-regular because of toxicity & $17(16 \%)$ & $18(21 \%)$ & $17(24 \%)$ & $22(55 \%)$ & $74(24 \%)$ \\
\hline \multirow[t]{3}{*}{ CHOP-R-ESC trials } & $n$ & 149 & 188 & 141 & 83 & 561 \\
\hline & Regular & $138(93 \%)$ & $173(92 \%)$ & $129(92 \%)$ & $66(80 \%)$ & $506(90 \%)$ \\
\hline & non-regular because of toxicity & $4(3 \%)$ & $10(5 \%)$ & $9(6 \%)$ & $14(17 \%)$ & $37(7 \%)$ \\
\hline
\end{tabular}

Remark: Regular course of chemotherapy means, patient received all planned cycles of chemotherapy. Non-regular course of chemotherapy because of toxicity means, patient received not all planned cycles of chemotherapy due to toxicity 


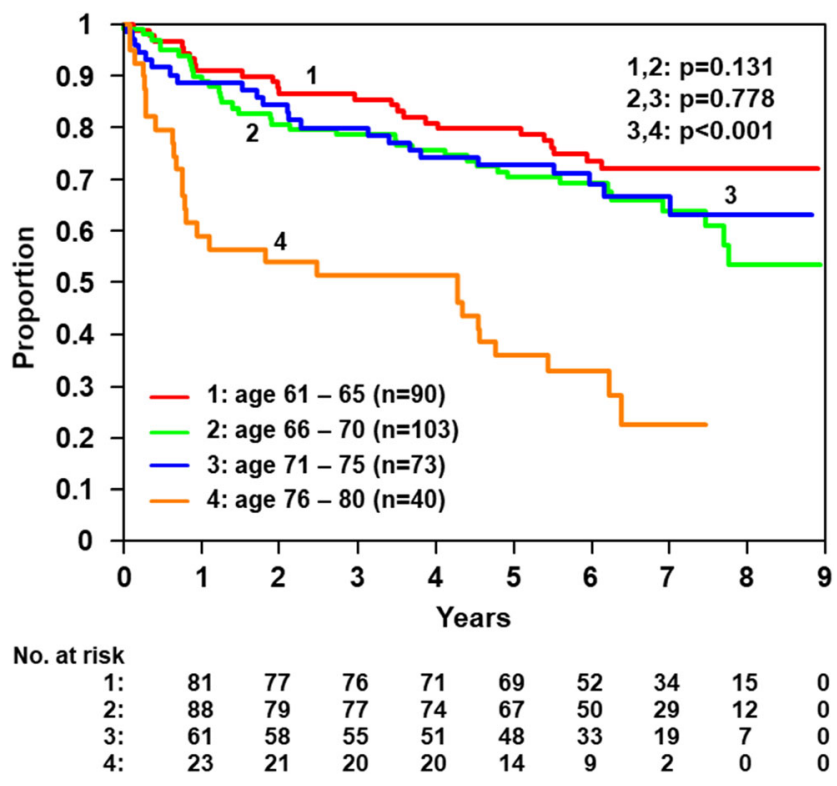

Fig. 3 OS according to age group RICOVER-60 study - age groups patients $61-80$ years, 6 -CHOP- $14+8 \times \mathrm{x}(n=306)$

6xCHOP-14 + 8xR $(28 \% ; p=0.005)$ (data within age groups: RICOVER-60 6xCHOP-14 + 8xR, 24\%, 20\%, 33\%, 44\%; RCHOP-ESC, $10 \%, 19 \%, 24 \%, 28 \%)$. The TRM was significant lower for the R-CHOP-ESC trials in comparison to the whole RICOVER-60 cohort ( $4 \%$ vs. $7 \%, p=0.038$ ). The TRM was reduced by almost $50 \%$ in the more recent R-CHOP-ESC trials compared to the original RICOVER-60 trial (for details see supplement Table 2).

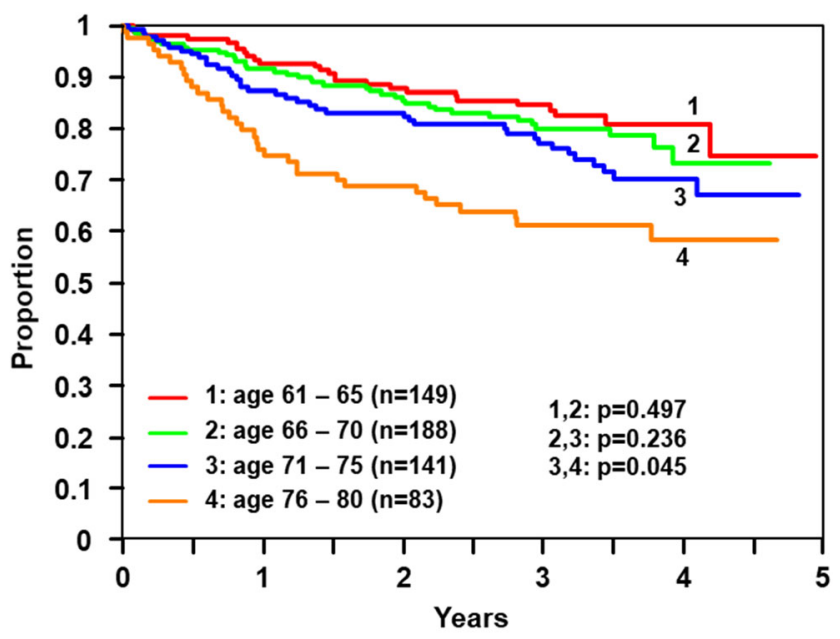

$\begin{array}{rccccc}\text { No. at risk } & 138 & 120 & 82 & 19 & 0 \\ \text { 1: } & 172 & 143 & 99 & 23 & 0 \\ 2: & 123 & 113 & 82 & 28 & 0 \\ 3: & 63 & 56 & 43 & 13 & 0\end{array}$

Fig. 4 OS according to age group CHOP-R-ESC trials - age groups patients $61-80$ years $(n=561)$

\section{Discussion}

Choosing the best treatment for elderly patients with aggressive lymphoma is a clinical challenge. The number of patients not treated at all still increases with age [13]. More frequently, the age-dependent increase of relevant comorbidities [14] leads to a substantial increase in patients receiving less than full-dose immunochemotherapy. On the other hand, several trials incorporating R-CHOP have shown that many elderly patients can be cured, depending, among others, on the dose and dose intensity of chemotherapeutic agents actually being administered $[2,3]$. If the relative dose intensity decreases below $70 \%$, the relapse rate increases dramatically $[5,15]$. As treatment-related toxicity dramatically increases with age, measures to decrease treatment-related morbidity and mortality in elderly patients are urgently needed.

Our analysis from a series of prospective multicenter trials is based on the R-CHOP-14 regimen administered at full doses. It shows that beyond the age of 75 years, there is a striking rise in TRM. One might speculate that the usage of CHOP-14 (instead of CHOP-21) regimen is responsible for this increase. However, there are currently no data available supporting this hypothesis. On the contrary, Cunningham et al. included patients in the same age group (56\% of pts. > 60 years, range 19 to 88 years) comparing R-CHOP-21 with R-CHOP-14 and demonstrated $g$ a higher infection rate in patients treated with R-CHOP-21. [16] The cut-off point of 75 years is among others supported by a retrospective analysis based on the SEER database in which the age above 75 years was identified as an independent risk factor for death within the first 30 days of treatment [17]. Therefore, measures to reduce toxicity and TRM in the elderly including a stringent antibiotic prophylaxis are of great importance for patients treated with immunochemotherapy. This might also be relevant for patients treated with R-CHOP-21 as the higher infection rate in these patients is possibly due to a lower rate of GCSF prophylaxis compared to the CHOP-14 trials. In patients between 76 and 80 years of age, we observed a cumulative TRM in the RICOVER-60 trial of 20\%. TRM dropped to $11 \%$ in the subsequent CHOP-R-ESC trials of the DSHNHL, although these trials used either higher doses and/or more frequent administration (DENSE-R, SEXIE-R) or an extended exposure time of rituximab (SMARTE-R). In the absence of randomized data, we hypothesize that a main reason for this improvement might be the introduction of a stringent infectious prophylaxis with a $>90 \%$ adherence in the CHOP-RESC trials. We found a TRM reduction by almost $50 \%$ (Table 3) compared to the RICOVER-60 study. The cut-off for an increased TRM in patients over the age of 75 years remained the same through all trials analyzed. We conclude that optimal supportive measures like the administration of prophylactic antibiotics, oral amphotericin $\mathrm{B}$, and virostatic agents enable the application of full-dose 
immunochemotherapy in larger fractions of elderly patients with less toxicity, leading to improved cure rates. Welldesigned strategies to select individualized prophylactic measures based on comorbidities and the history of a given patient are urgently needed. Data from prospective randomized trials for the increasing number of patients over 80 years are still missing. A phase II trial with a dose-reduced R-CHOP (RminiCHOP) showed promising results, with a 2 -year-PFS of $47 \%$ and OS of $59 \%$ [18]. Very recently, the data of a phase II trial applying ofatumumab in combination with miniCHOP and a mandatory prephase treatment with vincristine and prednisolone reported an improved 2 years OS of $64.7 \%$ [19]. The efficacy of bendamustine in elderly and frail patients is currently being analyzed. Park et al. published a smaller phase II trial with very modest results [20] and a median OS of 10.2 months and PFS of 5.4 months. The prospective B-R-ENDA phase II trial of the DSHNHL included pts over 80 years of age and pts being too frail to be included in the R-CHOP-ESC trials reported a 2-years OS of $42 \%$ [21]. Such studies and the results reported here highlight the clinical dilemma of treating elderly patients with aggressive lymphoma: efficacy is closely correlated with treatment intensity frequently resulting in high TRM. This analysis shows that a remarkable proportion of older patients, in particular those between $76-80$ years, can receive treatment comparable to younger patients. This proportion might further increase by further optimizing supportive measures. Supportive measures (pre-phase treatment, close surveillance, prophylactic anti-infective therapy) are highly effective when treating elderly pts with aggressive lymphoma and result in significantly better treatment outcome without changing immunochemotherapy. The challenge remains to identify those elderly pts who will benefit from standard treatment if optimal prophylaxis is administered, but avoid such treatment and lower dose and dose intensity in those patients who will not benefit even if optimal prophylaxis is administered. Supporting clinical decision-making by wider and consequent use of geriatric assessment scores might help to improve the treatment results in older patients without changing state-of-the-art immunochemotherapy [15]. Recent studies trying to improve treatment results for elderly patients with DLBCL by adding new drugs to R-CHOP have largely failed, in part, because patients on these combinations suffered from more and previously unknown severe infections. Particularly in these situations, the addition of consequent anti-infective prophylaxis may help to make treatment more feasible and safe enabling patients to benefit from the superior anti-lymphoma effects offered by combining immunochemotherapy with new targeted therapies.

Supplementary Information The online version contains supplementary material available at https://doi.org/10.1007/s00277-020-04345-3.
Authors' contributions F. Zettl and L. Trümper: designed the study, analyzed the data, and wrote the manuscript. M. Ziepert: designed the study, analyzed the data, performed the statistical analysis, and wrote the manuscript. B. Altmann and S. Zeynalova: performed the statistical analysis and wrote the manuscript. G. Held, V. Pöschel, G. Wulf, B. Glass, N. Schmitz, M. Loeffler, and K. Hohloch: wrote the manuscript

Funding Open Access funding enabled and organized by Projekt DEAL. This study was funded by Deutsche Krebshilfe (grant number 110884).

\section{Compliance with ethical standards}

Conflict of Interest Bertram Glass Roche AG research funding and honoraria, Gerhard Held Roche and Amgen research funding, Viola Poeschel Roche and Amgen travel grants, and Florian Zettl Roche travel grants.

Ethical approval All procedures performed in studies involving human participants were in accordance with the ethical standards of the institutional and/or national research committee and with the 1964 Helsinki declaration and its later amendments or comparable ethical standards.

Informed consent Informed consent was obtained from all patients for being included in the study.

Open Access This article is licensed under a Creative Commons Attribution 4.0 International License, which permits use, sharing, adaptation, distribution and reproduction in any medium or format, as long as you give appropriate credit to the original author(s) and the source, provide a link to the Creative Commons licence, and indicate if changes were made. The images or other third party material in this article are included in the article's Creative Commons licence, unless indicated otherwise in a credit line to the material. If material is not included in the article's Creative Commons licence and your intended use is not permitted by statutory regulation or exceeds the permitted use, you will need to obtain permission directly from the copyright holder. To view a copy of this licence, visit http://creativecommons.org/licenses/by/4.0/.

\section{References}

1. Pfreundschuh M, Kuhnt E, Trumper L, Osterborg A, Trneny M, Shepherd L, Gill DS, Walewski J, Pettengell R, Jaeger U, Zinzani PL, Shpilberg O, Kvaloy S, de Nully Brown P, Stahel R, Milpied N, Lopez-Guillermo A, Poeschel V, Grass S, Loeffler M, Murawski N, MabThera International Trial G (2011) CHOP-like chemotherapy with or without rituximab in young patients with good-prognosis diffuse large-B-cell lymphoma: 6-year results of an open-label randomised study of the MabThera International Trial (MInT) Group. Lancet Oncol 12(11):1013-1022. https://doi.org/10.1016/ S1470-2045(11)70235-2

2. Coiffier B, Lepage E, Briere J, Herbrecht R, Tilly H, Bouabdallah R, Morel P, Van Den Neste E, Salles G, Gaulard P, Reyes F, Lederlin P, Gisselbrecht C (2002) CHOP chemotherapy plus rituximab compared with CHOP alone in elderly patients with diffuse large-B-cell lymphoma. N Engl J Med 346(4):235-242. https://doi. org/10.1056/NEJMoa011795

3. Pfreundschuh M, Schubert J, Ziepert M, Schmits R, Mohren M, Lengfelder E, Reiser M, Nickenig C, Clemens M, Peter N, Bokemeyer C, Eimermacher H, Ho A, Hoffmann M, Mertelsmann R, Trumper L, Balleisen L, Liersch R, Metzner B, Hartmann F, Glass B, Poeschel V, Schmitz N, Ruebe C, Feller AC, Loeffler M (2008) Six versus eight cycles of bi-weekly 
CHOP-14 with or without rituximab in elderly patients with aggressive CD20+ B-cell lymphomas: a randomised controlled trial (RICOVER-60). Lancet Oncol 9(2):105-116. https://doi.org/10. 1016/s1470-2045(08)70002-0

4. Pfreundschuh $M$ (2010) How I treat elderly patients with diffuse large B-cell lymphoma. Blood 116(24):5103-5110. https://doi.org/ 10.1182/blood-2010-07-259333

5. Hirakawa T, Yamaguchi H, Yokose N, Gomi S, Inokuchi K, Dan K (2010) Importance of maintaining the relative dose intensity of $\mathrm{CHOP}-$ like regimens combined with rituximab in patients with diffuse large B-cell lymphoma. Ann Hematol 89(9):897-904. https:// doi.org/10.1007/s00277-010-0956-7

6. Taplitz RA, Kennedy EB, Bow EJ, Crews J, Gleason C, Hawley DK, Langston AA, Nastoupil LJ, Rajotte M, Rolston K, Strasfeld L, Flowers CR (2018) Outpatient management of fever and neutropenia in adults treated for malignancy: American Society of Clinical Oncology and Infectious Diseases Society of America Clinical Practice Guideline Update. J Clin Oncol 36(14):1443-1453. https://doi.org/10.1200/jco.2017.77.6211

7. Murawski N, Pfreundschuh M, Zeynalova S, Poeschel V, Hanel M, Held G, Schmitz N, Viardot A, Schmidt C, Hallek M, WitzensHarig M, Trumper L, Rixecker T, Zwick C (2014) Optimization of rituximab for the treatment of DLBCL (I): dose-dense rituximab in the DENSE-R-CHOP-14 trial of the DSHNHL. Ann Oncol 25(9):1800-1806. https://doi.org/10.1093/annonc/mdu208

8. Pfreundschuh M, Poeschel V, Zeynalova S, Hanel M, Held G, Schmitz N, Viardot A, Dreyling MH, Hallek M, Mueller C, Wiesen MH, Witzens-Harig M, Truemper L, Keller U, Rixecker T, Zwick C, Murawski N (2014) Optimization of rituximab for the treatment of diffuse large B-cell lymphoma (II): extended rituximab exposure time in the SMARTE-R-CHOP-14 trial of the german high-grade non-Hodgkin lymphoma study group. J Clin Oncol 32(36):4127-4133. https://doi.org/10.1200/jco.2013.54.6861

9. Pfreundschuh M, Murawski N, Zeynalova S, Ziepert M, Loeffler M, Hanel M, Dierlamm J, Keller U, Dreyling M, Truemper L, Frickhofen N, Hunerliturkoglu AN, Schmitz N, Poschel V, Rixecker T, Berdel C, Rube C, Held G, Zwick C (2017) Optimization of rituximab for the treatment of DLBCL: increasing the dose for elderly male patients. Br J Haematol 179(3):410-420. https://doi.org/10.1111/bjh.14860

10. Kaplan EL, Meier P (1958) Nonparametric estimation from incomplete observations. J Am Stat Assoc 53:457-481

11. DuBois DDE (1916) A formula to estimate the approximate surface area if height and weight be known. Arch Intern Med 17:86327

12. Wunderlich A, Kloess M, Reiser M, Rudolph C, Truemper L, Bittner S, Schmalenberg H, Schmits R, Pfreundschuh M, Loeffler M, German High-Grade Non-Hodgkin's Lymphoma Study G (2003) Practicability and acute haematological toxicity of 2- and 3-weekly CHOP and CHOEP chemotherapy for aggressive nonHodgkin's lymphoma: results from the NHL-B trial of the German High-Grade Non-Hodgkin's Lymphoma Study Group (DSHNHL). Ann Oncol 14(6):881-893

13. Hamlin PA, Satram-Hoang S, Reyes C, Hoang KQ, Guduru SR, Skettino S (2014) Treatment patterns and comparative effectiveness in elderly diffuse large B-cell lymphoma patients: a surveillance, epidemiology, and end results-medicare analysis. Oncologist 19(12):1249-1257. https://doi.org/10.1634/theoncologist.2014-0113
14. Sarkozy C, Coiffier B (2013) Diffuse large B-cell lymphoma in the elderly: a review of potential difficulties. Clin Cancer Res 19(7): 1660-1669. https://doi.org/10.1158/1078-0432.ccr-12-2837

15. Tucci A, Martelli M, Rigacci L, Riccomagno P, Cabras MG, Salvi F, Stelitano C, Fabbri A, Storti S, Fogazzi S, Mancuso S, Brugiatelli M, Fama A, Paesano P, Puccini B, Bottelli C, Dalceggio D, Bertagna F, Rossi G, Spina M (2015) Comprehensive geriatric assessment is an essential tool to support treatment decisions in elderly patients with diffuse large B-cell lymphoma: a prospective multicenter evaluation in 173 patients by the Lymphoma Italian Foundation (FIL). Leuk Lymphoma 56(4):921-926. https://doi. org/10.3109/10428194.2014.953142

16. Cunningham D, Hawkes EA, Jack A, Qian W, Smith P, Mouncey P, Pocock C, Ardeshna KM, Radford JA, McMillan A, Davies J, Turner D, Kruger A, Johnson P, Gambell J, Linch D (2013) Rituximab plus cyclophosphamide, doxorubicin, vincristine, and prednisolone in patients with newly diagnosed diffuse large B-cell non-Hodgkin lymphoma: a phase 3 comparison of dose intensification with 14-day versus 21-day cycles. Lancet 381(9880):18171826. https://doi.org/10.1016/S0140-6736(13)60313-X

17. Olszewski AJ, Mantripragada KC, Castillo JJ (2016) Risk factors for early death after rituximab-based immunochemotherapy in older patients with diffuse large B-cell lymphoma. J Natl Compr Cancer Netw 14(9):1121-1129

18. Peyrade F, Jardin F, Thieblemont C, Thyss A, Emile JF, Castaigne S, Coiffier B, Haioun C, Bologna S, Fitoussi O, Lepeu G, Fruchart C, Bordessoule D, Blanc M, Delarue R, Janvier M, Salles B, Andre M, Fournier M, Gaulard P, Tilly H, Groupe d'Etude des Lymphomes de l'Adulte i (2011) Attenuated immunochemotherapy regimen (R-miniCHOP) in elderly patients older than 80 years with diffuse large B-cell lymphoma: a multicentre, single-arm, phase 2 trial. Lancet Oncol 12(5):460-468. https://doi.org/10.1016/S14702045(11)70069-9

19. Peyrade F, Bologna S, Delwail V, Emile JF, Pascal L, Ferme C, Schiano JM, Coiffier B, Corront B, Farhat H, Fruchart C, Ghesquieres H, Macro M, Tilly H, Choufi B, Delarue R, Fitoussi O, Gabarre J, Haioun C, Jardin F (2017) Combination of ofatumumab and reduced-dose CHOP for diffuse large B-cell lymphomas in patients aged 80 years or older: an open-label, multicentre, single-arm, phase 2 trial from the LYSA group. Lancet Haematol 4(1):e46-e55. https://doi.org/10.1016/s2352-3026(16)30171-5

20. Park SI, Grover NS, Olajide O, Asch AS, Wall JG, Richards KL, Sobol AL, Deal AM, Ivanova A, Foster MC, Muss HB, Shea TC (2016) A phase II trial of bendamustine in combination with rituximab in older patients with previously untreated diffuse large B-cell lymphoma. Br J Haematol 175(2):281-289. https://doi.org/10. 1111/bjh.14232

21. Zettl F, Braulke F, Ziepert M, Viardot A, Kahl C, Prange-Krex G, Korfel A, Dreyling MH, Illmer T, Birkmann J, Wedding U, Reichert D, Md W, Hartmann F, Hurtz H-J, Schmitz N, Witzens-Harig M, Klapper W, Rosenwald A, Poeschel V, Loeffler M, Wulf G, Altmann B, Truemper L (2019) Rituximab and bendamustine for first-line treatment of frail or elderly patients with aggressive B-cell lymphoma: final results of the prospective phase-II Brenda trial of GLA (German Lymphoma Alliance). Blood 134(Supplement_1):4073

Publisher's note Springer Nature remains neutral with regard to jurisdictional claims in published maps and institutional affiliations. 